This item was submitted to Loughborough's Research Repository by the author.

Items in Figshare are protected by copyright, with all rights reserved, unless otherwise indicated.

\title{
Urinary nandrolone metabolite detection after ingestion of a nandrolone precursor
}

PLEASE CITE THE PUBLISHED VERSION

http://dx.doi.org/10.1249/MSS.0b013e31818edaeb

PUBLISHER

Lippincott, Williams \& Wilkins (๔ American College of Sports Medicine)

VERSION

AM (Accepted Manuscript)

LICENCE

CC BY-NC-ND 4.0

REPOSITORY RECORD

Watson, Phillip, Catherine Judkins, Ed Houghton, Caroline Russell, and Ronald J. Maughan. 2019. "Urinary Nandrolone Metabolite Detection After Ingestion of a Nandrolone Precursor". figshare.

https://hdl.handle.net/2134/11374. 
This item was submitted to Loughborough's Institutional Repository (https://dspace.lboro.ac.uk/) by the author and is made available under the following Creative Commons Licence conditions.

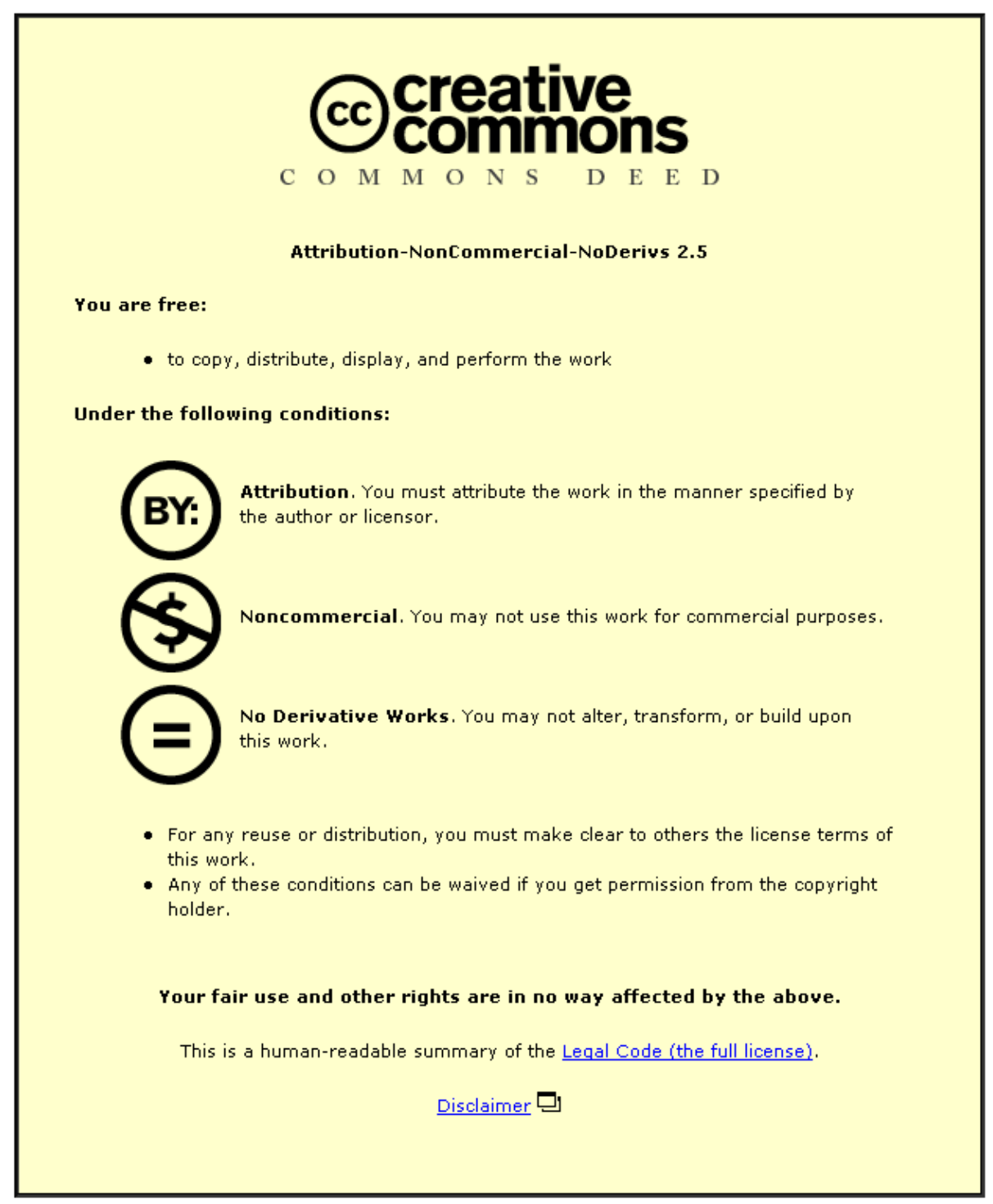

For the full text of this licence, please go to: http://creativecommons.org/licenses/by-nc-nd/2.5/ 


\section{Urinary nandrolone metabolite detection after ingestion of a nandrolone precursor}

Phillip Watson ${ }^{1}$, Catherine Judkins ${ }^{2}$, Ed Houghton ${ }^{2}$, Caroline Russell, ${ }^{2}$ Ronald J Maughan ${ }^{1}$

${ }^{1}$ School of Sport and Exercise Sciences, Loughborough University, Loughborough. UK.

LE11 3TU

${ }^{2}$ Drug Surveillance Group, HFL Sport Science, Newmarket Road, Fordham, Cambridgeshire.

UK. CB7 5WW

Correspondence: Professor Ronald Maughan,

School of Sport and Exercise Sciences,

Loughborough University,

Leicestershire,

LE11 3TU,

United Kingdom.

Telephone: $\quad$ +44(0)1509226329

Fax: $\quad+44(0) 1509226301$

Email: $\quad$ r.j.maughan@lboro.ac.uk

Running title: Supplement contamination with 19-nor

Disclosure of funding: This study was funded by UK Sport. 


\section{Abstract}

Introduction Quantities of various anabolic/ androgenic steroids have been found in dietary supplements without their presence being disclosed on the label. The aim of this study was to quantify the excretion patterns of the diagnostic metabolites, 19-norandrosterone (19-NA) and 19-noretiocholanolone (19-NE), after ingestion of small doses of 19-nor-4-androstene-3,17dione (19-norandrostenedione). Methods Eleven males and nine females entered the laboratory in the morning following an overnight fast. An initial urine sample was collected and volunteers then ingested $500 \mathrm{~mL}$ of water containing $5 \mathrm{~g}$ of creatine monohydrate and either $1.0 \mu \mathrm{g}, 2.5 \mu \mathrm{g}$ or $5.0 \mu \mathrm{g}$ of 19 -norandrostendione. The volume of each urine void was measured and an aliquot taken. Samples were analysed for the metabolites 19-NA and 19-NE by GCMS. Results Baseline urinary 19-NA concentrations were $0.19 \pm 0.14 \mathrm{ng} / \mathrm{mL}$. Ingestion of the supplement resulted in peak mean urinary $19-\mathrm{NA}$ concentrations of $0.68 \pm 0.36 \mathrm{ng} / \mathrm{mL}$, $1.56 \pm 0.86 \mathrm{ng} / \mathrm{mL}$, and $3.89 \pm 3.11 \mathrm{ng} / \mathrm{mL}$ in the $1.0 \mu \mathrm{g}, 2.5 \mu \mathrm{g}$ or $5.0 \mu \mathrm{g}$ trials respectively. Under current WADA regulations, ingestion of the $1.0 \mu \mathrm{g}$ dose produced 0 positive doping tests, 5 subjects (20\%) tested positive in the $2.5 \mu \mathrm{g}$ trial and 15 subjects $(75 \%)$ had urinary 19 NA concentrations exceeding $2 \mathrm{ng} / \mathrm{mL}$ after ingesting creatine containing $5.0 \mu \mathrm{g}$ of the steroid. The recovery of the ingested dose was highly variable between individuals, with values ranging from $11-84 \%($ mean $\pm \mathrm{SD}=47 \pm 18 \%)$. Conclusions Ingestion of trace amounts of 19-norandrostendione can result in transient elevations of urinary 19-NA and 19NE concentrations. The addition of as little as $2.5 \mu \mathrm{g}$ of 19 -norandrostendione to a supplement $(0.00005 \%$ contamination $)$ appears sufficient to result in a doping violation in some individuals.

Key Words: 19-norandrostenedione, steroids, drugs in sport, World Anti Doping Agency 


\section{Introduction}

Paragraph 1 The profile of sport has never been higher than it is today, but the issue of drug use by elite sportsmen and women has cast a cloud over the integrity of sporting competition. At the time of the 2004 Olympic Games in Athens, Noakes (15) suggested that the widespread use of performance-enhancing drugs had fundamentally distorted sporting contests. Although relatively few athletes test positive in doping controls it is argued that evasion of such controls is not difficult. Over the last few years, however, evidence has emerged that some athletes who fail doping tests, though technically guilty of a doping offence, did not set out to cheat.

Paragraph 2 Around the year 2000, several high profile cases of athletes producing urinary levels of nandrolone metabolites in excess of the threshold of $2 \mathrm{ng} / \mathrm{mL}$ permitted by the doping regulations prompted a wide scale investigation of this steroid. These investigations raised the possibility that some positive tests may have resulted from ingestion of contaminated sport supplements. Geyer and colleagues (7) reported the presence of anabolic/androgenic steroids in almost $15 \%$ of a sample of 634 commercially available dietary supplements tested, without their presence being disclosed on the label. Further reports have confirmed these findings, identifying varying amounts of nandrolone, testosterone and other steroids in a wide variety of non-hormonal dietary supplements $(6,18)$. The reasons for the presence of these substances in dietary supplements are not fully understood. Some cases may result from cross-contamination from other products due to inadequate quality control practices at the site of manufacture, but the presence of high doses of steroids and stimulants in some products makes it is impossible to rule out the deliberate addition of these substances to improve the efficacy of a product (13). 
Paragraph 3 Nandrolone is the popular name for the anabolic-androgenic steroid more properly known as 19-nortestosterone. This latter name makes it clear that this drug is closely related, in both structure and function, to the male sex hormone testosterone, which plays a key role in the maintenance of muscle mass and strength, bone health, libido, some aspects of cognitive function and in aggressive behaviour. Because of this close association, nandrolone has been used by athletes in an attempt to accelerate muscle growth, increase strength, enhance aggression and improve recovery (10). The removal of the 19-methyl group from testosterone to produce nandrolone enhances the anabolic properties relative to the androgenic properties. Thus, many of the adverse side effects consequent to the use of testosterone are not observed with nandrolone, and the liver toxicity is significantly reduced when compared to the use of some other anabolic steroids.

Paragraph 4 The use of nandrolone itself has been prohibited by the International Olympic Committee (and subsequently by WADA) since 1988, but 19-norandrostenedione and 19norandrostenediol, the metabolic precursors of nandrolone, were added to the prohibited list only in 2001. The WADA diagnostic test for nandrolone relies on the measurement in the athlete's urine sample of the metabolite 19-norandrosterone (19-NA) rather than the parent compound itself. Detection of urine concentrations of $19-\mathrm{NA}$ in excess of $2 \mathrm{ng} / \mathrm{mL}$ is considered a breach of WADA regulations, and the principle of strict liability means that the athlete who provides a positive sample is guilty of a doping offence unless it can be proven otherwise. The situation is complicated by the fact that 19-NA can be derived either from nandrolone itself, or from 19-norandrostenedione or 19-norandrostenediol, the metabolic precursors of nandrolone. Oral ingestion of these precursors does not appear to influence body composition or strength (19) though it can cause a small increases in circulating levels of 
nandrolone (12). While injection of nandrolone esters results in a positive urine test for some months, oral ingestion of nandrolone is quickly cleared from the body (2).

Paragraph 5 Several studies have examined the urinary excretion of nandrolone metabolites following the ingestion of dietary or over-the-counter supplements known to contain nandrolone or its precursors $(3,4,6,5,16)$. Positive tests for nandrolone, with peak urinary 19-NA concentrations of up to $623 \mathrm{ng} / \mathrm{mL}$, were reported following the ingestion of supplements including chrysin, tribulus terrestris and guarana, none of which should result in an adverse doping test (7). Significant elevations in urinary 19-NA concentrations have been reported following ingestion of dietary supplements that were known to contain 19norandrostenedione and/or 19-norandrostenediol $(3,16)$, over-the-counter androstenedione products (4) and therapeutic administration of eye drops (1). The interpretation of these data is, however, often clouded by uncertainty as to the exact composition of the supplements, relatively short urine collection periods and, in some cases, small sample sizes of only male volunteers.

Paragraph 6 We have recently examined the urinary excretion of nandrolone metabolites following the ingestion a single daily dose of $10 \mu \mathrm{g}$ of 19 -norandrostendione added to a creatine supplement, administered to 18 male and female volunteers over a 6 day period (9). These data demonstrated that the ingestion of 19-norandrostenedione, at a level of contamination as low as $0.0002 \%$, resulted in a doping violation in all volunteers on at least one test day. Peak urine 19-NA concentrations ranged from $1.3-28.0 \mathrm{ng} / \mathrm{mL}(\mathrm{mean} \pm \mathrm{SD}=$ $7.4 \pm 6.9 \mathrm{ng} / \mathrm{mL}$ ), with the greatest levels observed in either the first or second void following ingestion of the contaminated supplement (within four hours after ingestion). In most subjects, levels fell below the $2 \mathrm{ng} / \mathrm{mL}$ threshold for a positive doping test in all subsequent 
samples. Given the rapid appearance of these metabolites in the urine following supplement ingestion, and the relatively short time course during which a positive doping result would be obtained, this may raise an issue over the timing of doping tests.

Paragraph 7 In light of these findings, and of a report by Geyer et al. (6) suggesting that a dose of 19-norandrostendione as low as $1 \mu \mathrm{g}$ may result in a urinary 19-NA concentration in excess of $2 \mathrm{ng} / \mathrm{mL}$, the aim of the present study was to examine the urinary excretion pattern of the nandrolone metabolites specific to WADA screening following $1 \mu \mathrm{g}, 2.5 \mu \mathrm{g}$ and $5 \mu \mathrm{g}$ doses of 19-norandrostendione in a large group of both male and female subjects. The quantity of 19-norandrostenedione administered in this study is representative of the amount previously reported as an undeclared contaminant in some dietary supplements $(6,7)$. Given the speculation surrounding positive doping cases being attributed to ingestion of sports supplements contaminated with pro-hormones, this presents an important consideration for both athletes and doping agencies, as well as for supplement manufacturers.

\section{Methods}

Paragraph 8 Eleven male and nine female healthy volunteers (Mean \pm SD age $25 \pm 4$ y, height $1.68 \pm 0.06 \mathrm{~m}$, body mass $68.6 \pm 13.1 \mathrm{~kg}$, BMI $24.2 \pm 3.2 \mathrm{~kg} . \mathrm{m}^{-2}$ ) were recruited to participate in this study. All were recreationally active, but none were engaged in competitive sport at the time of the investigation and none were liable to testing by any sporting body for abuse of drugs. The study was approved by Loughborough University Ethical Advisory Committee (Reference No: R05-P39) and all subjects gave written consent to participate after being fully informed of the nature of the study. Volunteers completed a questionnaire 
outlining their habitual use of dietary supplements, and were requested to refrain from ingestion of any supplements for the duration of the study.

Paragraph 9 On three occasions, separated by at least three days, subjects entered the laboratory in the morning following an overnight fast. An initial urine sample was collected and body mass was measured. Subjects then ingested $500 \mathrm{~mL}$ of water (Highland Spring, Perthshire, UK) containing $5 \mathrm{~g}$ of creatine monohydrate (Arena Pharmaceuticals, Buckingham, UK) and either $1.0 \mu \mathrm{g}, 2.5 \mu \mathrm{g}$ or $5.0 \mu \mathrm{g}$ of 19-norandrostendione (SigmaAldrich, St Louis MO, USA). The treatment was randomised and administered in a singleblind crossover manner. The drinks were indistinguishable with regard to appearance and taste. The creatine supplement had previously been analysed using a validated supplement screening method and was shown to be free of nandrolone and related precursor materials 19norandrostenedione and 19-norandrostenediol (limit of detection of $2 \mathrm{ng} / \mathrm{g}$ ).

Paragraph 10 Following ingestion of the drink, subjects were provided with a volumetric cylinder, a series of labelled sterile collection tubes and a urine collection diary. Subjects were instructed to collect and measure the volume of each void passed during the day, and to retain a $30 \mathrm{~mL}$ sample in a numbered collection tube. The time of the void and the total volume were entered into a collection diary. On the following morning, the urine samples were collected from the subjects and stored frozen at $-80^{\circ} \mathrm{C}$ ready for analysis. Subjects were not required to collect urine samples at any specific times after ingestion of the supplement, as the aim was to monitor the response to free-living conditions. No restrictions on food and fluid intake were in place during the sample collection period, but all subjects generally followed similar routines and similar eating and drinking patterns for each trial. To help ensure metabolic conditions were similar before each trial, subjects were instructed to record dietary 
intake and physical activity during the day before the first trial, and to replicate this in the day prior to the subsequent experimental trials. No supplement or alcohol consumption was permitted in the 24 hours before and during each trial and subjects were also asked to avoid unaccustomed or strenuous exercise during this time.

Paragraph 11 All samples were analysed quantitatively for the metabolites 19-NA and 19NE, relative to a ${ }^{2} \mathrm{H}_{4}-19-\mathrm{NA}$ internal marker. In accordance with WADA guidelines, the specific gravity and $\mathrm{pH}$ of all samples were recorded prior to analysis. Samples were analysed using a validated and ISO 17025 accredited method developed for the quantitative analysis of 19-NA using GCMS (Shimadzu QP2010, Valcobond VB-5 column) in line with WADA requirements (Technical document - TD2004NA). Following enzyme hydrolysis using E. coli (20), sample preparation was carried out using solid phase extraction to yield an eluate which was treated to form the enol-trimethylsilyl (TMS) derivative. Each sample batch was analysed alongside 2 sets of controls (19-NA and 19-NE at 2 and $8 \mathrm{ng} / \mathrm{mL})$ and a set of calibration $(0$, $1,2,5,7,10 \mathrm{ng} / \mathrm{mL}$ ) samples. The mass spectrometer was operated in the selected ion mode (SIM) monitoring ions $\mathrm{m} / \mathrm{z} 405$ for 19-NA and 19-NE and m/z 409 for the deuterated analogue of 19-NA. Samples were quantified for both metabolites using XCALIBUR LCQUAN software. For the purposes of doping testing, WADA guidelines suggest that a correction should be applied to 19-NA and 19-NE concentrations when urine specific gravity exceeds 1.020. All 19-NA and 19-NE data in the present manuscript are presented without correction for urine specific gravity, unless otherwise stated.

Paragraph 12 Calibration Lines and Controls: All calibration curves in all assays $(\mathrm{n}=5)$ were well within the established acceptance criteria for the quantitative method (all points within $\pm 15 \%$ of the nominal value). The $\mathrm{R}^{2}$ value for the 19 -NA calibration curve was 
$0.998 \pm 0.001(\% \mathrm{CV}=0.06)$ and for $19-\mathrm{NE}$ was $0.993 \pm 0.002(\% \mathrm{CV}=0.17)$. Low control $(2$ $\mathrm{ng} / \mathrm{mL})$ and high control $(8 \mathrm{ng} / \mathrm{mL})$ samples were extracted alongside each assay. The mean \pm SD low control sample over the five batches of samples analysed $(n=26)$ was $2.00 \pm 0.19 \mathrm{ng} / \mathrm{mL}$ for $19-\mathrm{NA}(\% \mathrm{CV}=9.3)$ and $2.08 \pm 0.22 \mathrm{ng} / \mathrm{mL}$ for $19-\mathrm{NE}(\% \mathrm{CV}=10.5)$. The mean \pm SD high control $(\mathrm{n}=26)$ was $7.89 \pm 0.4 \mathrm{ng} / \mathrm{mL}$ for $19-\mathrm{NA}(\% \mathrm{CV}=5.1)$ and $8.16 \pm 0.63 \mathrm{ng} / \mathrm{mL}$ for $19-\mathrm{NE}(\% \mathrm{CV}=7.7)$.

Paragraph 13 Data are presented as mean \pm SD unless otherwise stated. To identify differences in normally distributed results, one-factor analysis of variance (ANOVA) was employed. Statistical significance was accepted at $\mathrm{P}<0.05$.

\section{Results}

Paragraph 14 Urine samples: Cumulative urine volume over the each of the 3 trial periods was $1767 \pm 539 \mathrm{~mL}, 2107 \pm 1126 \mathrm{~mL}$ and $1860 \pm 758 \mathrm{~mL}$ in the $1.0 \mu \mathrm{g}, 2.5 \mu \mathrm{g}$ and $5.0 \mu \mathrm{g}$ trials respectively. The mean daily volume of urine produced during the trials was not influenced by gender (Male $1.86 \pm 0.94 \mathrm{~L} /$ day; Female $1.98 \pm 0.72 \mathrm{~L} /$ day; $\mathrm{P}=0.562$ ). Baseline urinary 19-NA concentrations were $0.19 \pm 0.14 \mathrm{ng} / \mathrm{mL}$. None of the urine samples collected from subjects prior to the ingestion of the supplement contained levels of 19-NA or 19-NE exceeding the limit of quantification of the assay used in this study for urine analysis $(0.5 \mathrm{ng} / \mathrm{mL})$, hence these values must be considered as estimates. The mean concentration of these values was $0.19 \pm 0.14 \mathrm{ng} / \mathrm{mL}$. 
Paragraph 15 Figure 1 shows urine 19-NA concentrations for a typical subject over the 3 trials. An increase in the major metabolite, 19-NA, was detected in urine samples produced by all subjects following the ingestion of the supplement at all levels of contamination, with a significant correlation found between the dose ingested and peak urinary 19-NA concentrations $\left(\mathrm{r}^{2}=0.593, \mathrm{P}<0.001\right)$. Mean peak 19-NA concentrations in the $1.0 \mu \mathrm{g}, 2.5 \mu \mathrm{g}$ or $5.0 \mu \mathrm{g}$ trials are presented in Table 1. Peak urinary 19-NA concentrations were observed within $6 \mathrm{~h}$ of sample ingestion, with levels falling below the threshold of detection before the end of the day in all subjects. In most (19/60) cases, the peak urinary 19-NA concentration was observed in the first or second sample passed after ingestion. There was a large interindividual variability in the peak values observed, but peak concentrations $(5.0 \mu \mathrm{g}$ trial $\mathrm{P}=$ $0.030)$ and amount excreted $(5.0 \mu \mathrm{g}$ trial $\mathrm{P}=0.085)$ were higher in the male than in the female volunteers. The 24 hour 19-NA profiles in the trials are presented in Figure 2, which shows the concentration of 19-NA excreted in each sample provided by the volunteers. There was no evidence of any correlation between peak urinary 19-NA levels in the $5.0 \mu \mathrm{g}$ trial and body mass $\left(\mathrm{r}^{2}=0.44 ; \mathrm{P}=0.052\right)$ or total daily urine output $\left(\mathrm{r}^{2}=-0.52 ; \mathrm{P}=0.827\right)$.

Paragraph 16 The excretion profiles of 19-NE were broadly similar to those of 19-NA. However, only minor changes in urine concentration were observed following ingestion of the supplement contaminated with $1 \mu \mathrm{g}$ of 19 -norandrostenedione $(\mathrm{P}=0.710)$. In the $2.5 \mu \mathrm{g}$ and 5 $\mu \mathrm{g}$ trials, peak urinary $19-\mathrm{NE}$ levels of $0.53 \pm 0.33 \mathrm{ng} / \mathrm{mL}$ and $1.16 \pm 0.71 \mathrm{ng} / \mathrm{mL}$, respectively, were observed. All pre-ingestion urinary 19-NE levels were below the limit of quantification of the assay. The median (range) urinary concentration ratio of 19-NE to 19NA was $0.33(0.00-1.92)$ at baseline. The ingestion of 19-norandrostendione produced no significant change in this ratio, with values of $0.23(0.00-0.63), 0.28(0.15-0.62)$ and 0.30 
$(0.15-0.94)$ observed at the time of peak urinary 19-NA concentration in the $1 \mu \mathrm{g}, 2.5 \mu \mathrm{g}$ and $5 \mu \mathrm{g}$ trials respectively $(1 \mu \mathrm{g}$ trial $\mathrm{P}=0.151 ; 2.5 \mu \mathrm{g}$ trial $\mathrm{P}=0.872 ; 5 \mu \mathrm{g}$ trial $\mathrm{P}=0.588)$.

Paragraph 17 The recovery of the ingested dose was determined on the basis of the administered amount of 19-norandrostenedione and the quantity of metabolites 19-NA $+19-$ NE measured in the urine. The \% recovery of 19-NA and 19-NE across all trials ranged from $7-68 \%($ mean $\pm \mathrm{SD}=37 \pm 15)$ and $3-29 \%($ mean $\pm \mathrm{SD}=11 \pm 6)$ respectively. The $\%$ total recovery of $19-\mathrm{NA}+19-\mathrm{NE}$ ranged from $11-84 \%($ mean $\pm \mathrm{SD}=47 \pm 18)$, but there was a clear inverse relationship between the dose ingested and percentage total recovery $(1.0 \mu \mathrm{g}$ trial, $55 \pm 19 \% ; 2.5 \mu \mathrm{g}$ trial, $46 \pm 14 \% ; 5.0 \mu \mathrm{g}$ trial, $40 \pm 19 \% ; \mathrm{P}<0.001)$. When samples with concentrations below the limit of quantification $(0.5 \mathrm{ng} / \mathrm{mL})$ were excluded from this analysis, there was no difference in the total recovery of each supplement $(1.0 \mu \mathrm{g}$ trial $34 \pm 21 \% ; 2.5$ $\mu \mathrm{g}$ trial $38 \pm 16 \% ; 5.0 \mu \mathrm{g}$ trial $38 \pm 19 \% ; \mathrm{P}=0.763)$. The total recovery was lower in females $(42 \pm 16 \%)$ than in the male $(52 \pm 19 \%)$ volunteers $(\mathrm{P}=0.029)$

Paragraph 18 To assess the risk of an athlete committing a doping offence, the urinary 19NA concentration data were corrected where necessary for specific gravity of the sample according to WADA requirements (WADA Technical Document TD2004NA). The peak corrected urinary 19-NA values in the $1.0 \mu \mathrm{g}, 2.5 \mu \mathrm{g}$ and $5.0 \mu \mathrm{g}$ trials are presented in Figure 3. This correction caused no change to the overall findings observed for the uncorrected values i.e. the $1.0 \mu \mathrm{g}$ dose would still have produced 0 positive doping tests, whereas 5 subjects $(20 \%)$ would have tested positive in the $2.5 \mu \mathrm{g}$ trial and $15(75 \%)$ had urinary $19-\mathrm{NA}$ concentrations exceeding $2 \mathrm{ng} / \mathrm{mL}$ after ingesting $5.0 \mu \mathrm{g}$. 


\section{Discussion}

Paragraph 19 The results of the present study demonstrate that ingestion of trace quantities of 19-norandrostenedione can increase urinary concentrations of the nandrolone metabolites, 19-NA and 19-NE, with as little at $2.5 \mu \mathrm{g}$ of 19-norandrostenedione resulting in urinary 19NA concentrations in excess of the WADA threshold for a positive doping test of $2 \mathrm{ng} / \mathrm{mL}$ in some individuals. There was a clear dose-dependent response, with a significant correlation between the amount of 19-norandrostenedione ingested and the subsequent peak 19-NA concentration measured in the urine $\left(\mathrm{r}^{2}=0.593, \mathrm{P}<0.001\right)$. The $2.5 \mu \mathrm{g}$ dose corresponds to a level of contamination in the creatine supplement of $0.00005 \%$. To put this in perspective, pharmaceutical GMP (Good Manufacturing Practice) requirements specify that impurities as low as $0.01 \%$ must be detectable; the level of contamination in the $2.5 \mu \mathrm{g}$ trial is 200 times less than this standard. This highlights the importance of specialised supplement testing that can detect impurities prohibited by the sports regulatory authorities at concentrations significantly lower than those detectable by standard GMP requirements. The potential for such low levels of contamination in a supplement to result in an adverse finding raises significant concerns for the manufacture of dietary supplements intended for consumption by athletes liable to regular doping tests.

Paragraph 20 A previous study from our laboratory demonstrated that an acute $10 \mu \mathrm{g}$ dose of 19-norandrostenedione resulted in urinary 19-NA concentrations significantly above the 2 $\mathrm{ng} / \mathrm{mL}$ threshold in all subjects (9). Peak urine 19-NA concentrations were highly variable, but an individual peak 19-NA concentration of $28.0 \mathrm{ng} / \mathrm{mL}$ was recorded and the greatest 19NA levels were observed in either the first or second void following ingestion of the supplement. Several previous studies have also reported similar findings following the 
ingestion of dietary supplements or over-the-counter medicines either known to contain nandrolone, or its precursors, or where the presence of these substances was undeclared (3-7, 16).

Paragraph 21 The present study shows that ingestion of trace quantities of this pro-hormone results in a transient increase in urine metabolite concentration, with peak 19-NA concentrations seen in either the first or second urine void following supplement ingestion in all subjects (within 6 hours). This is very different from the response seen following intramuscular injection of nandrolone esters, which results in elevated urinary 19-NA concentrations for several months (2). Ingestion of a large dose of 19-norandrostenedione (50 mg: 10000 times the highest dose used in the present study) has been reported to increase urine 19-NA and 19-NE concentrations for up to 7-10 days (17), but clearance of a $25 \mathrm{mg}$ oral dose of ${ }^{13} \mathrm{C}$-nandrolone appears to follow an excretion rate similar to that seen in this present study, with urinary metabolite concentrations returning to baseline within $20 \mathrm{~h}$ after ingestion (3). The quantities of 19-norandrostendione administered in the present study are many times smaller than that administered by Uralets and Gillette, but are representative of the amounts that have been reported to be present in dietary supplements without the disclosure on the label $(6,7)$.

Paragraph 22 Given the number of positive doping cases in which athletes have cited contaminated sports supplements as the cause, this presents a serious issue for both athletes and doping agencies. For example, an individual tested soon after the ingestion of a contaminated supplement may test positive for nandrolone use, but the same athlete tested later in the day (e.g. $>10 \mathrm{~h}$ after supplementation) would provide a clean sample. With athletes often taking some supplements $2-3$ times daily, it is reasonable to expect that concentrations 
of urinary nandrolone metabolites could remain elevated throughout the day, increasing the risk of a positive doping outcome in the presence of contamination.

Paragraph 23 The present study, in accordance with previous data $(3,9)$, demonstrated large inter-individual variation in both peak urinary 19-NA concentrations and percentage recovery of the ingested dose. Differences in cumulative urine volume may explain some of the variation in the peak values observed in the present study. The rate of urine production and its composition are influenced by several factors, including glomerular filtration rate and the secretion and reabsorption in the promixal and distal tubules and collection ducts, in response to changes in plasma osmolality and blood pressure (14). It has been suggested that the ingestion of large volumes of fluid may result in an under-estimation of excreted doping substances, due to the production of dilute urine (3). Correction of measured concentrations to account for concentrated urine samples is permitted by the WADA regulations (WADA Technical Document TD2004NA), but it is not clear how dilute urine samples are accounted for. While there was a large inter-individual variability in the peak 19-NA values observed, there was no evidence for any correlation between total daily urine output $\left(\mathrm{r}^{2}=-0.52 ; \mathrm{P}=\right.$ 0.827 ) and peak urinary $19-\mathrm{NA}$ levels in the $5.0 \mu \mathrm{g}$ trial. Peak values were consistently higher in the male volunteers than in the females $(\mathrm{P}=0.030)$, even though urine volumes were not different, suggesting a gender-related difference in the metabolism or excretion of these compounds. The reasons for the variation between individuals are not entirely clear. It might be expected that males would have lower peak 19-NA concentrations due to a greater body mass and, more particularly, a greater lean tissue mass (though this was not measured) giving a greater distribution space and therefore lower concentration in tissues. It might also be expected that males would have a greater water turnover, including a greater urine output that would lead to dilution of the excreted metabolites (11), but this was not the case. 
Paragraph 24 The recovery of the ingested dose was highly variable, ranging from about 11 $84 \%$ across all subjects during the three trials. Similar findings have been reported in several studies investigating the excretion patterns of urinary nandrolone metabolites $(3,4)$. There was a clear inverse relationship between the quantity of 19-norandrostenedione ingested and total percentage recovery of 19-NA $+19-\mathrm{NE}$, but this association was not apparent when values under the limit of quantification were excluded from this analysis. As concentrations measured below $0.5 \mathrm{ng} / \mathrm{mL}$ can only be considered as estimations, perhaps this association is not as strong as it appeared initially. A third metabolite, 19-norepiandrosterone, might account for at least part of the ingested dose that was not recovered. This metabolite is excreted in a sulphate-conjugated form and would not be detected by the analytical method used in the present study (2) which is based on the methods recommended by WADA to detect nandrolone use. It is not at present known what fraction of an ingested dose will be excreted as 19-norepiandrosterone. Some of the inter-individual variability in total recovery may also be accounted for by failure to collect all urine passed, despite stressing the importance of this to the subjects. The completeness of the urine collections could not be verified by reference to the $24 \mathrm{~h}$ urinary creatinine excretion, because of the confounding factor introduced by the relatively large $(5 \mathrm{~g})$ dose of creatine ingested along with the dose of 19-norandrostenedione, but all subjects reported complete compliance over the collection periods. Although the inter-individual variability recovery in the present study was large, it was generally relatively consistent between repeated trials with the same individual.

Paragraph 25 The total fractional recovery was lower in females $(42 \pm 16 \%)$ than in the male $(52 \pm 19 \%)$ volunteers $(\mathrm{P}=0.029)$. The apparent differences in the fractional recovery of the ingested dose may be related to a gender-specific difference in the metabolic fate of ingested norsteroids, so that there is either a greater production of the metabolite 19- 
norepiandrosterone in females, and/or a greater fractional excretion of 19-NA and 19-NE as the sulphate, rather than glucuronic acid, conjugates. Normal excretion of 19-NA appears to vary during the menstrual cycle, with the highest values reported during ovulation, suggesting a link between steroid metabolism and oestrogen levels in females (8). The difference in urinary excretion patterns between males and females in this present study is consistent with the findings of our previous study (9), and warrants further investigation.

Paragraph 26 The present data demonstrate that the presence of 19-norandrostendione at a concentration as low as $0.00005 \%$ in a $500 \mathrm{~mL}$ liquid supplement can result in a doping violation under current WADA regulations in some individuals. Furthermore, the marked variation in peak urinary 19-NA concentrations raises the possibility that some athletes ingesting a product contaminated with a low amount of 19-norandrostenedione could fail a drugs test, whereas others taking the same product may not. The level of pro-hormone contamination administered was many times lower than reported to be present in some commercially-available supplements and it is clear that these data have serious implications for the production of dietary supplements on sale to athletes. Unless manufacturers are able to carry out analysis to detect contamination at the level of $1 \mu \mathrm{g}$ per serving - irrespective of the serving size - they cannot provide any assurance that their product is free from the risk of an adverse doping result. A routine test for supplements undertaken in our laboratory can detect steroid concentrations of $10 \mathrm{ng} / \mathrm{g}$ (i.e. $0.000001 \%$ contamination in a product may be detected). The elimination of 19-norandrostendione was rapid, with peak urinary concentrations of 19-NA and 19-NE generally occurring in either the first or second urine void (within 6 hours) after supplement ingestion. The rapid clearance of these metabolites from the body following the oral ingestion of nandrolone precursors also raises an important issue for both athletes and doping agencies regarding the timing doping tests. 


\section{Acknowledgements}

The authors gratefully acknowledge the financial support of UK Sport. The results of the present study do not constitute endorsement by ACSM.

\section{References}

1 Avois L, Mangin P, Saugy M. Concentrations of nandrolone metabolites in urine after the therapeutic administration of an ophthalmic solution. J Pharm Biomed Anal. 2007;44:173-9.

2 Ayotte C, Guay C, Cleroux M, Goudereault D, Fakirian A. Origin of elevated levels of norandrosterone in human urine: half-truths vs facts. In: Schänzer W, Geyer H, Gotzmann A, Mareck U, editors. Recent advances in doping analysis (10). Köln: Sport und Buch Strauß; 2002. p.13-21.

3 Baume N, Avois L, Schweizer C, Cardis C, Dvorak J, Cauderay M, Mangin P, Saugy M. [13C]Nandrolone excretion in trained athletes: interindividual variability in metabolism. Clin Chem. 2004;50:355-64.

4 Catlin DH, Leder BZ, Ahrens B, Starcevic B, Hatton CK, Green GA, Finkelstein JS. Trace contamination of over-the-counter androstenedione and positive urine test results for a nandrolone metabolite. JAMA. 2000;284:2618-21. 
5 Delbeke F, van Eenoo P, van Thuyne W, Desmet N. Prohormones and sport. J Steroid Biochem Mol Biol. 2002;83:245-51.

6 Geyer H, Mareck-Engelke U, Reinhart U, Thevis M, Schänzer W. Positive doping cases with norandrosterone after application of contaminated nutritional supplements. Deutsche Z Sportmed. 2000;51:378.

7 Geyer H, Parr MK, Mareck U, Reinhart U, Schrader Y, Schanzer W. Analysis of nonhormonal nutritional supplements for anabolic-androgenic steroids - results of an international study. Int J Sports Med. 2004;25:124-9.

8 Hemmersbach P, Hågensen AH, Misund J. Determination of urinary norandrosterone excretion in females during one menstrual cycle by gas chromatography/mass spectrometry. Biomed Chromatogr. 2006;20:710-7.

9 Judkins C, Watson P, Russell C. A crossover study of 19-nor-androstenedione contamination in sports supplements: preliminary findings. In: Schänzer W, Geyer H, Gotzmann A, Marek U, editors. Recent Advances in Doping Analysis. Vol 14. Koln: Sportverlag Strauss; 2006. p. 477-480

10 Lambert MI, St Clair Gibson A. Anaboli-androgenic steroids: effects on muscle size and strength. South African J Sports Med. 1995;2:6-9.

11 Lentner C. Geigy Scientific Tables, Volume 1. Basel: Ciba-Geigy Limited; 1981. p. 274 
12 Machnik M, Schrader Y, Schanzer W. Plasma levels of 19-norsteroids after oral and buccal administration of norandrostenedione. In: Schänzer W, Geyer H, Gotzmann A, Mareck U, editors. Recent advances in doping analysis (10). Köln: Sport und Buch Strauß; 2002. p. 125-32.

13 Maughan RJ. Contamination of dietary supplements and positive drugs tests in sport. $J$ Sports Sci. 2005;23:883-889.

14 Maughan RJ, Nadel ER. Temperature regulation and fluid and electrolyte balance. In: Maughan RJ, editor. Nutrition in Sport. Oxford, UK: Blackwell Science; 2000. p. 20315.

15 Noakes TD. Tainted glory-doping and athletic performance. N Engl J Med. 2004;26, $351: 847-9$.

16 Tseng YL, Kuo F-H, Sun H-H. Quantification and profiling of 19-norandrosterone and 19-noretiocholanolone in human urine after consumption of a nutritional supplement and norsteroids. J Anal Toxicol. 2005;29:124-34.

17 Uralets VP, Gillette PA. Over-the-counter anabolic steroids 4-androsten-3,17-dione; 4-androstene-3beta,17beta-diol; and 19-nor-4-androsten-3,17-dione: excretion studies in men. J Anal Toxicol. 1999;23:357-66.

18 Van der Merwe PJ, Grobbelaar E. Unintentional doping through the use of contaminated nutritional supplements. South African Med J. 2005;95:510. 
19 van Gammeren D, Falk D, Antonio J. Effects of norandrostenedione and norandrostenediol in resistance-trained men. Nutrition. 2002;18:734-7.

20 Dumasia MC. In vivo biotransformation of 17a-methyltestoserone in the horse revisited: identification of 17-hydroxymethyl metabolites in equine urine by capillary gas chromatography/mass spectrometry. Rapid Communications in Mass Spectrometry 2003;17:320-329. 


\section{Figure Legends}

Figure 1: Typical urinary 19-NA excretion profile for a single subject taking a creatine supplement spiked with 1.0, 2.5 and $5.0 \mu \mathrm{g}$ 19-norandrostenedione.

Figure 2: Urinary 19-NA excretion for all subjects on the 1.0 (top), 2.5 (middle) and 5.0 (bottom) $\mu \mathrm{g}$ 19-norandrostenedione trials.

Figure 3: Peak urinary 19-NA concentrations on each trial. These data have been corrected where necessary for specific gravity of the sample according to the procedures required by WADA. The dotted line marks the $2 \mathrm{ng} / \mathrm{ml}$ level that constitutes a doping violation under current WADA rules. 


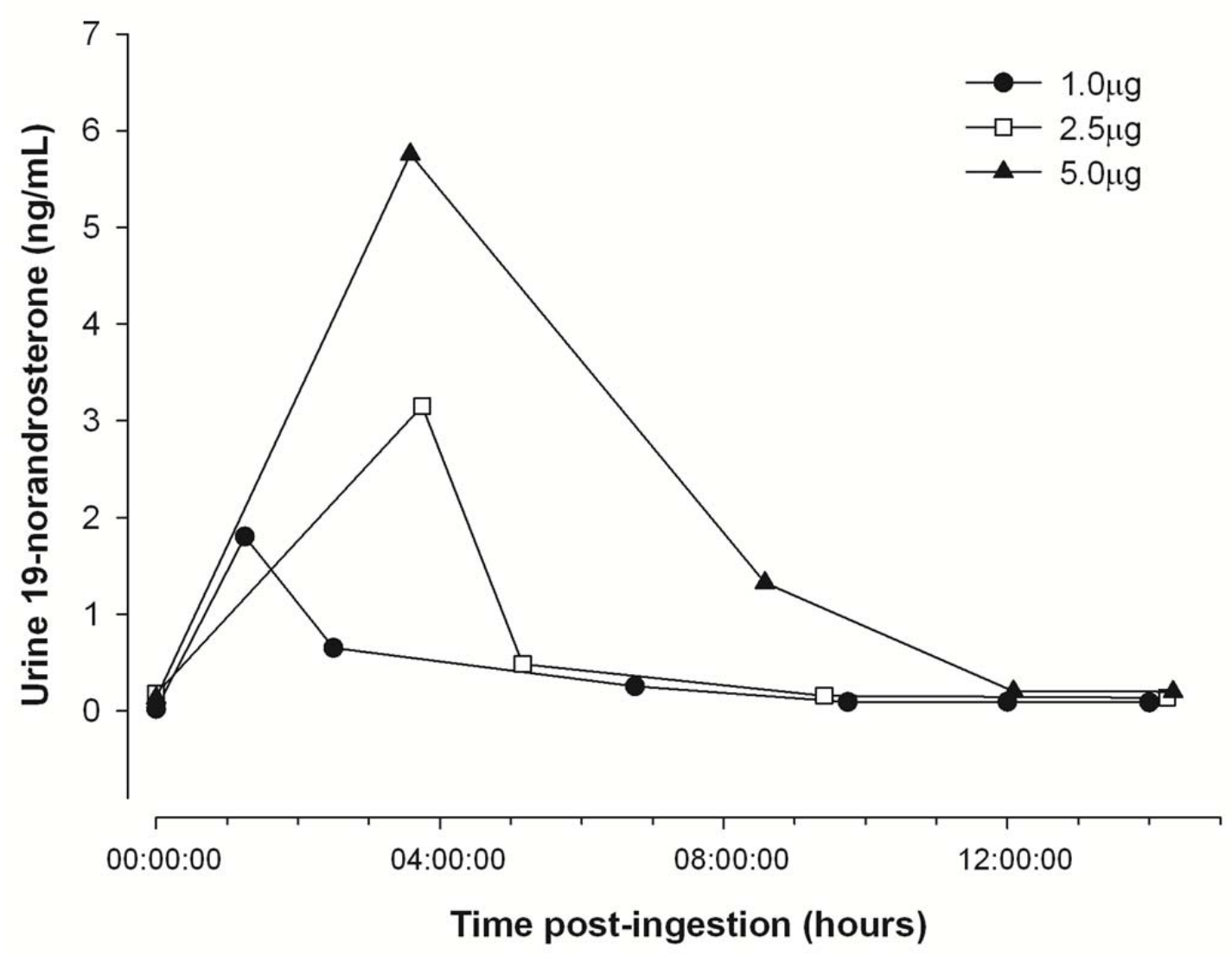



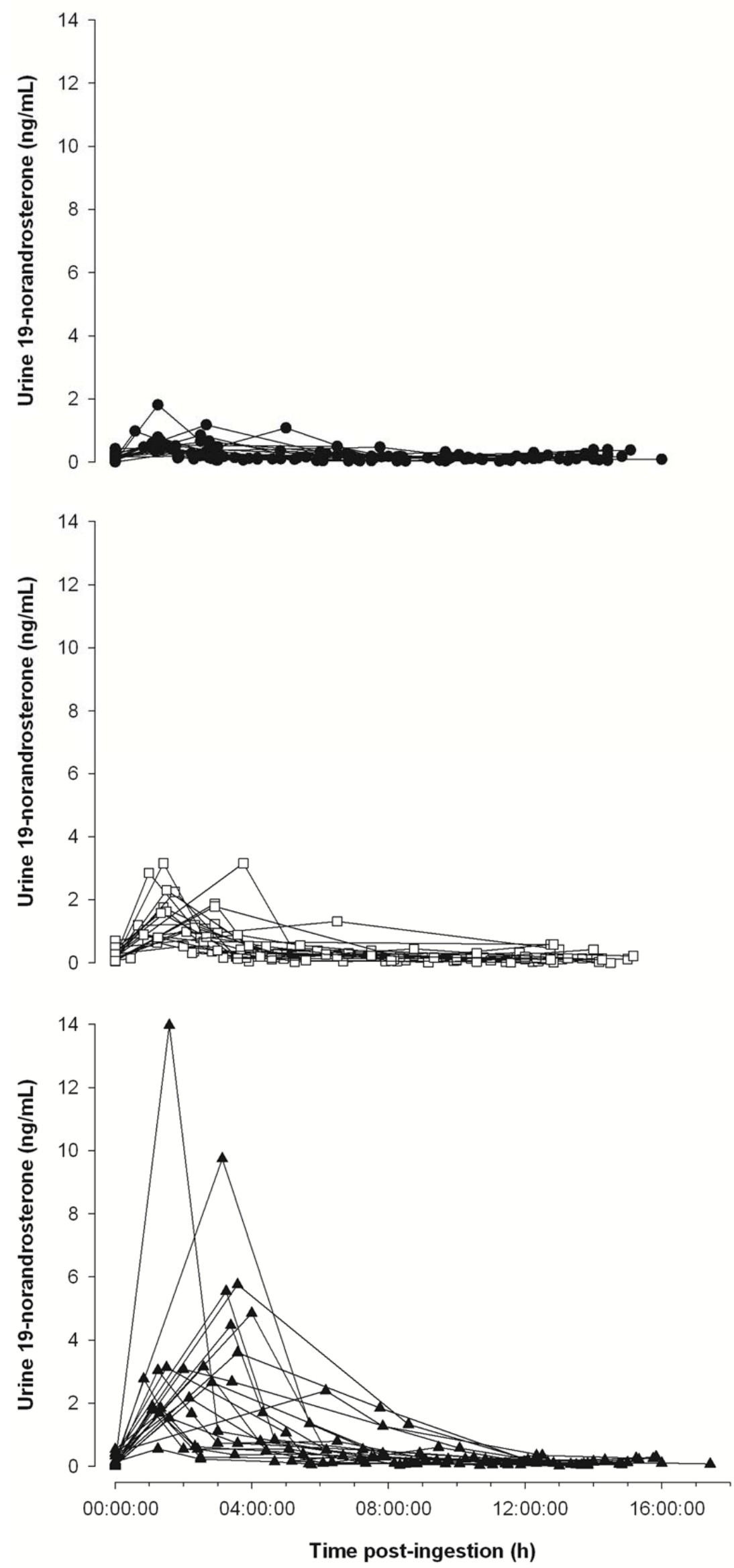


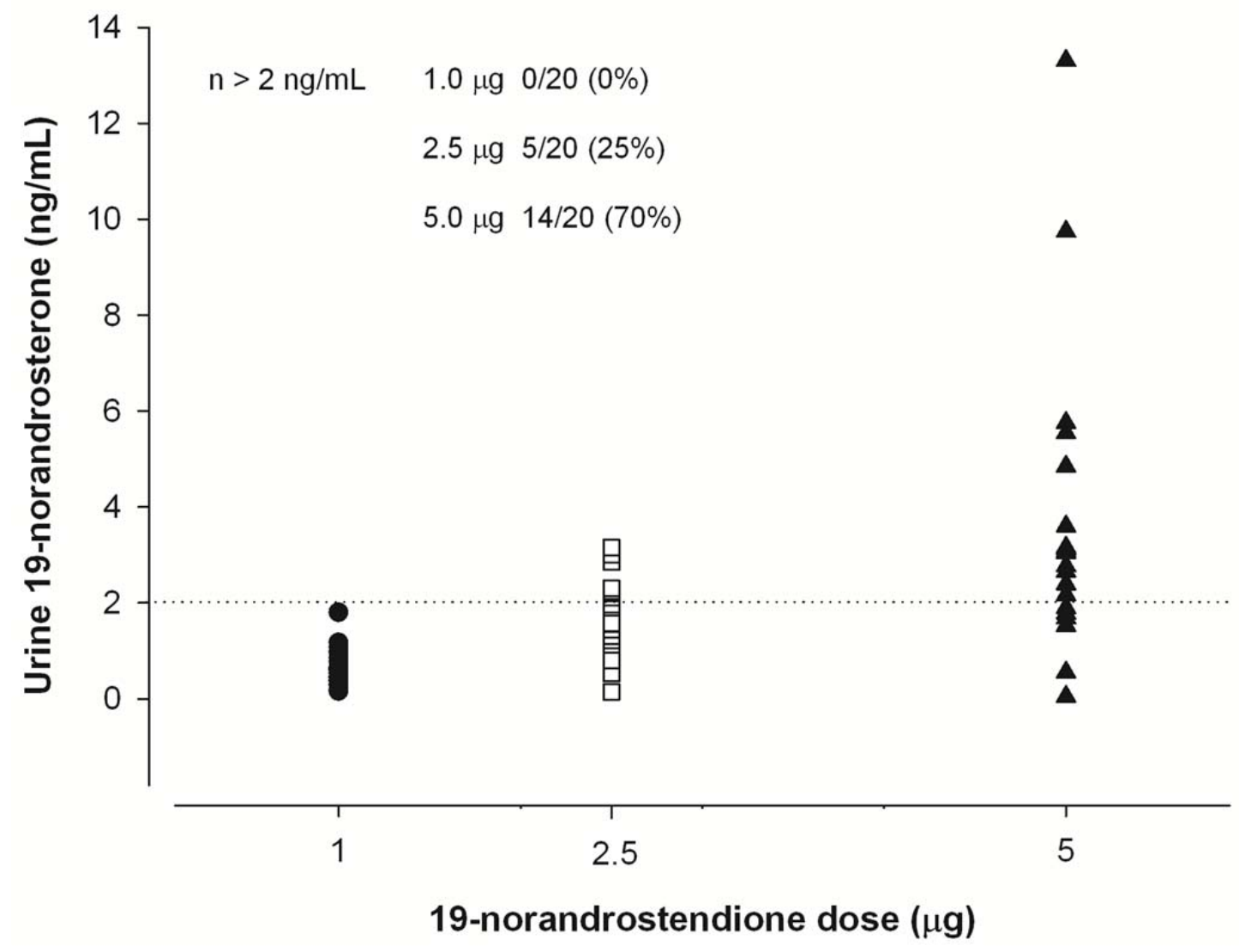


Table 1: Peak urinary 19-norandrosterone (19-NA) concentrations observed during the $1.0 \mu \mathrm{g}$, $2.5 \mu \mathrm{g}$ and $5.0 \mu \mathrm{g}$ trials $(\mathrm{ng} / \mathrm{mL})$. Data are presented for the entire subject group $(\mathrm{n}=20)$ and divided into male $(n=11)$ and female $(n=9)$ subgroups.

\begin{tabular}{lccc}
\hline & $\mathbf{1 . 0}$ & $\mathbf{2 . 5}$ & $\mathbf{5 . 0}$ \\
\hline Total & $0.68 \pm 0.36$ & $1.56 \pm 0.86$ & $3.89 \pm 3.11$ \\
Males & $0.84 \pm 0.42$ & $1.89 \pm 0.86$ & $5.13 \pm 3.66$ \\
Females & $0.48 \pm 0.09$ & $1.17 \pm 0.61$ & $2.37 \pm 2.37$ \\
\hline
\end{tabular}

